\title{
Transfers of vulnerability through adaptation plan implementation: an analysis based on networks of feedback control loops
}

\author{
Olivier Barreteau $^{1}, \underline{\text { John M. Anderies }}^{2}{ }^{2}$ Chloe Guerbois $^{3}{ }^{3}$ Tara Quinn $^{4}$, Clara Therville $^{1,5,6,7}, \underline{\text { Raphael Mathevet }}^{5,8}$ and Francois $^{\text {Bo }}$
} Bousquet $^{6,7}$

\begin{abstract}
With the increasing number of adaptation plans being generated across the world at multiple scales and levels of organization, the issue of coordination among plans is emerging as a significant challenge. We focus on how lack of coordination may constrain their efficiency as a result of potential transfers of vulnerability. This paper focuses on interdependencies between autonomous feedback control loops that represent adaptation processes and makes the link between autonomous action and (social-ecological) system levels. These interdependencies allow changes in vulnerability of one adaptation actor as a consequence of the reduction of vulnerability of another actor. We refer to the processes behind such changes as "vulnerability transfers" and suggest the need for their identification so that actors may make agreements to address them explicitly. A thorough analysis of each step involved in a feedback control loop enables the identification of potential interdependencies, leading to seven basic types of vulnerability transfer. The analysis of example cases of observed transfers of vulnerability in three coastal case studies then demonstrate the suitability of feedback control loop networks to assess, ex-ante, potential vulnerability transfers. The example cases feature all types of theoretically possible vulnerability transfers. Initial empirical investigation showcases the relative importance of shared infrastructures in generating transfers of vulnerability. It also helps to reveal forgotten links to avoid decreasing efficiency of adaptation processes beyond each autonomous agent's jurisdiction. Our representation contributes to a more comprehensive ex-ante identification of transfers and hence the possibility to discuss and manage them.
\end{abstract}

Key Words: coastal areas vulnerability; externalities; feedback control loop; infrastructures; interdependences; robustness

\section{INTRODUCTION}

With the consequences of global change expected to become increasingly acute in the coming decades there has been a proliferation of adaptation planning across organizational levels and various organizational types (Adger et al. 2009a). Cities, counties, regions, and sectors are generating plans with weak, if any, coordination with other organizations (Oberlack 2017). These plans often conflate with, or readdress, what was previously known as development plans, and can distort development objectives (Cannon and Müller-Mahn 2010). Meanwhile global change processes open windows of opportunity for reforms or complete reorganization (Folke et al. 2010) that may enhance traditional development objectives (Bisaro and Hinkel 2016). Lack of coordination, one of the main barriers to adaptation, requires consistency between actions undertaken at autonomous individual as well as collective levels.

In this paper, we consider adaptation in the context of global change. For the term "adaptation," we include both development and adaptation, because both mobilize for transformation (Bousquet et al. 2016), and characterize processes of intentional change of (individual, technological) practices (i) to respond to alterations of the environment: ecological, climatic, social (Smit and Pilifosova 2003) and (ii) to manage exposure and vulnerability (Pielke 1998). There is a myriad of possible adaptation actions (Adger et al. 2005), all of which may have potential consequences beyond the jurisdiction of the entities where they are carried out (Adger et al. 2009b, Challies et al. 2014) ranging from local spillovers to global teleconnections. We suggest that these unintended consequences of adaptation processes fall under the umbrella of vulnerability transfer, a term we define further in the following paragraph, because they may lead to a redistribution of vulnerabilities (Atteridge and Remling 2018). A vulnerability transfer is a consequence of an interdependency between autonomous adaptation actors (individuals, organizations, groups) implementing adaptation plans, either because the actors have connected interests or are operating in a joint environment. This situation is considered as a source of "maladaptation" (Barnett and O'Neill 2010). This term is also used by the IPCC to qualify situations of failure of adaptation ${ }^{[1]}$. For the sake of clarity we stick to characterizing the processes rather than the outcome. We need then tools for identifying potential processes of vulnerability transfer, at least qualitatively. The overall objective of this work is (1) to make explicit the links and interdependencies between autonomous adaptation actors, and (2) to provide support for discussions about vulnerability transfers and delineate the limits of the system under consideration in order to prevent tensions and inefficiencies at a larger scale. In doing so, we connect the action-oriented and system-oriented perspectives that are opposed in Eisenack and Stecker (2012): action is considered at the autonomous agent level while the system is considered via the scope of interdependencies.

We outline a framework that may contribute to such vulnerability assessments and test it with empirical observations. Here we define vulnerability following Turner et al. (2003:8074):

${ }^{1}$ G-EAU, Univ Montpellier, AgroParisTech, Cirad, IRD, INRAE, Montpellier SupAgro, Montpellier, France, ${ }^{2}$ School of Sustainability and School of Human Evolution and Social Change, Arizona State University, Tempe, AZ, ${ }^{3}$ Nelson Mandela University, Sustainability Research Unit, George, South Africa, ${ }^{4}$ College of Life and Environmental Sciences, University of Exeter, UK, ${ }^{5}$ CEFE, CNRS, Univ Montpellier, Univ Paul Valéry, EPHE, IRD, Montpellier, France, ${ }^{6}$ CIRAD, UPR GREEN, Montpellier, France, ${ }^{7}$ GREEN, Université de Montpellier, Cirad, Montpellier, France, ${ }^{8}$ Institut Français de Pondichéry, CNRS/MAEE, Pondicherry, India 


\begin{abstract}
"Vulnerability is the degree to which a system, subsystem, or system component is likely to experience harm due to exposure to a hazard, either a perturbation or stress/stressor." We define a vulnerability transfer, then, as an increase in the vulnerability of community $y$ due to actions taken by community $x$ to decrease its own vulnerability, while Atteridge and Remling (2018) speak of "redistribution" due to adaptation. However, vulnerability is not necessarily conserved during transfers; the vulnerability of community $y$ after a transfer is not necessarily equal to its vulnerability before transfer plus the change in vulnerability of community $x$. Because relations of autonomous adaptation actors to their environment are diverse, positive transfers may also occur, and synergies should also be accounted for (Adger et al. $2009 b$ ). Several conceptual frameworks have already dealt with the issue of side effects of policies or actions: externalities (Dahlman 1979), nonmarket values (Bark 2011), virtual water (Kumar and Singh 2005), off-site costs (Khan et al. 2008), systemic risks (Centeno et al. 2015), ecological solidarity (Mathevet et al. 2016), and telecoupling (Friis et al. 2016). These frameworks are seeking to attribute the origin of a problem through monitoring of flows and/or addressing global issues because of interdependencies between rather large and loosely defined systems.
\end{abstract}

Our goal is to address the consequences of these interdependencies from the range of adaptation actions that are quickly emerging. Vulnerability may be transferred when one autonomous adaptation actor changes conditions of another while attempting to reduce her own vulnerability. We build on a network of action situations involving these autonomous adaptation actors to map potential interdependencies and systemic feedbacks. Our aim is to uncover the mechanisms behind them. These transfers may lead to an increase of instances of injustice as well as inefficiencies at higher levels of organization. To elicit these interdependencies and their pathways, we build a generalizable list of possible transfers based on the mechanisms through which they may occur. We draw on theory from feedback systems to identify theoretical types and use case studies to provide examples of their occurrence. Our approach should help improve identification of interdependencies as highlighted by Atteridge and Remling (2018) as well as the underlying mechanisms, both on a theoretical and an empirical basis.

After a brief review of existing concepts used to characterize transfers of vulnerability, we introduce a representation of community adaptation through a network of regulatory feedback control loops (Anderies 2015), and draw from it possible mechanisms for transfers to occur. We then put the theoretically elaborated list of possible mechanisms to a trial through case studies in coastal areas in France, the United Kingdom, and South Africa. These case studies enable us to reflect on the usefulness of this typology of vulnerability transfers and draw out some preliminary principles that this representation enables, including some ideas for improving governance.

\section{VULNERABILITY TRANSFERS AS AN EXTENSION OF EXTERNALITIES AND SPILLOVERS}

Here we take quick stock of existing frameworks and theories that aim to describe spillovers resulting from actions of agents that generate impacts beyond their jurisdiction, variably referred to as externalities, environmental leakages, ancillary effects, offsite costs or benefits, systemic risks, territorial ecology, telecoupling, and CPR management problems. There is a huge literature on these issues $(\sim 140 \mathrm{~K}$ references with at least one of these terms on google scholar, see Klein et al. 2014 for a review) and there are several requests in the literature to integrate their assessment into place-based ecosystem services assessment (Pascual et al. 2017). Working with vulnerability transfers as a common concept enables researchers and stakeholders to formalize them with a common vocabulary. This paves the way for an analysis in a common frame, a prerequisite for a solidarity approach to collaborative governance (Mathevet et al. 2018a). Moreover, to the best of our knowledge, all the approaches mentioned above are used ex-post. Identifying ex-ante interdependencies that pave the way for potential vulnerability transfers may help prevent failures from occurring. In the diagnostic procedure suggested by Oberlack and colleagues (2018) to operationalize telecoupled systems and polycentric governance for integrated analysis, we focus mainly on two steps (out of seven): identifying flows that link regions (or systems) and establishing the network of linked action situations through which they are instantiated (other steps are rather focusing on institutional analysis and distant consequences).

\section{Identification of "spillovers"}

The notion of externalities from economics is at the root of transfers of vulnerability seen as the consequences of the adaptation process of one group on another groups' adaptation capacity, exposure, and sensitivity (Stringer et al. 2006, Osbahr et al. 2010). At larger geographical scales, telecoupling addresses how new policies in one place have consequences in distant places (Friis et al. 2016). Most, if not all, of these conceptual frameworks are based on the existence of flows (information, material, energy) from one place or one system to another.

Most flows considered in this literature are spatial, either locally for physical flows or, as in the telecoupling literature, over a longer range for informational or financial flows. More recently, some flows have been considered across social groups (Eakin et al. 2014) or temporal scales. All these flows are enabled by interdependencies between actors (Paavola and Adger 2005).

Pushing the identification of flows further, territorial ecology seeks to identify all flows generated or needed by a process, which might be induced by a component of a land system (Loiseau et al. 2013). These methods filter out transfers that cannot be explained through a flow of something (e.g., material, information, money) and typically lead to input-output matrix analysis (Lutter et al. 2016).

Finally, the literature also explores interdependencies that are not based on flows. Among other framings, problems stated as common-pool resources (Ostrom 1990, 2005) feature interdependencies through the availability of a resource that is dependent on actions of several autonomous decision makers. All these types of interdependencies may drive vulnerability transfers when one decision maker involved in an interaction makes a change whose impacts reach another decision maker. In such cases, interdependencies feature a network of adjacent action situations (McGinnis 2011, McGinnis and Ostrom 2014) through which vulnerabilities can be transferred. 


\section{Establishing and handling a network of action situations}

Managing these interdependencies to prevent the emergence of tensions between various actors and actor groups has been the focus of integrated resource management for at least 30 years. Many integrated approaches assume, as in stewardship approaches and ethics, a benevolent social planner, i.e., a steward of the future, that is able to allocate resources optimally for all needs while taking into account interactions between coupled systems (Mathevet et al. 2018a). It could be a government body (Osberghaus et al. 2010), a legitimate regulator (Eisenack 2016), or a mix of public action and collective action in the management of natural resources (Mathevet et al. 2018b). However such integration is difficult for four reasons: (1) special interests and power struggles, (2) lack of suitable arenas to manage interactions between systems, (3) persistence of inconsistencies when boundaries are drawn to make an object manageable, and (4) situations in which it is not possible to collect further information to deal with uncertainties at particular scales. Solutions based on coordination across scales seem to be more promising (Daniell and Barreteau 2014, Guerrin et al. 2014) and often fit propositions that characterize polycentric governance (Ostrom 1999).

In this paper, we aim to disaggregate the analysis of adaptation processes at the level of autonomous entities in order to identify the suitable governance levels to be included in the analysis (Paavola and Adger 2005). These autonomous entities are able to act in order to target a goal, monitor success in reaching this goal, and possibly revise action patterns accordingly in pursuit of this goal. Following ideas from complexity science that recognize the absence of a global controller in any economic system (Arthur et al. 1997), as well as the observation of inefficacy of centralized decisions that would ignore the autonomy of adaptive agents (Nagendra and Ostrom 2012), we assume that there is an irreducible plurality of autonomous decision centers with their own goals that drive their own adaptation processes. A "contested social political process" (Eriksen et al. 2015:524) is emerging from the interactions among these adaptation processes. Oberlack and Eisenack (2018) describe cases with an observed lack of coordination leading to constraints to some actors' adaptation capacity. Hereafter, we elaborate a conceptual generic model to support the qualification of these social political processes intertwined with physical flows.

\section{A GENERIC MODEL OF VULNERABILITY TRANSFER}

Vulnerability transfers are driven by interdependencies. We thus first consider the network of adaptation actors as they are connected through various interdependencies, then we describe the dynamics of each autonomous adaptation actor. As we aim to develop tools for the ex-ante identification of potential vulnerability transfers, our strategy is to elaborate theoretical types of interdependencies to serve as guidelines when assessing adaptation plans. The core focus of our approach to studying vulnerability transfer is the identification of a list of theoretically possible interdependencies between adaptation processes, which might enable transfers of vulnerability.

\section{Social-ecological systems (SES) as networks of regulatory feedback control loops}

Here we build on Anderies (2015) to represent an SES as a network of feedback control loops (FBCL). We consider that each agent (autonomous adaptation actor) endorses a specific set of separate and possibly competing goals. In each agent-goal pair, the goal component drives a set of actions, i.e., asset allocation, performed by the agent through a set of infrastructures that transform these actions into goods and services. Goals are characterized by a domain of interest, a governance level, a reference area, a spatial scale, and a typical time scale.

The elementary feedback loop shown in Figure 1 is generated by an agent, whether an individual, group, or organization within a given SES, and driven by a particular goal she is attempting to manage. All agents typically generate several independent FBCLs, unless they are able to formalize a composite goal. It may also be the case that an agent who is a member of an organization may act independently and generate an FBCL while the organization generates another FBCL at the same time. Beside the goals, a FBCL features an asset allocation process conditioned by decision infrastructures, including institutional arrangements, knowledge systems, and value systems, a "plant" (a set of infrastructures that translates asset allocation actions into outcomes), and monitoring capacity. That is, the agent considers the infrastructures at her disposal and decides to use them to generate the expected outputs fitting her goal according to the resources allocated. Although infrastructures considered as components of the plant may evolve, they typically will not change radically at the FBCL time scale.

Fig. 1. Representation of a component of a social-ecological system (SES) as an elementary feedback control loop (FBCL), adapted from Anderies 2015. Note "C" in the circle to the left represents "comparison" of the goal to the actual measured outcome. In feedback control, "C" is often simply the difference between the goal measure and output measure.

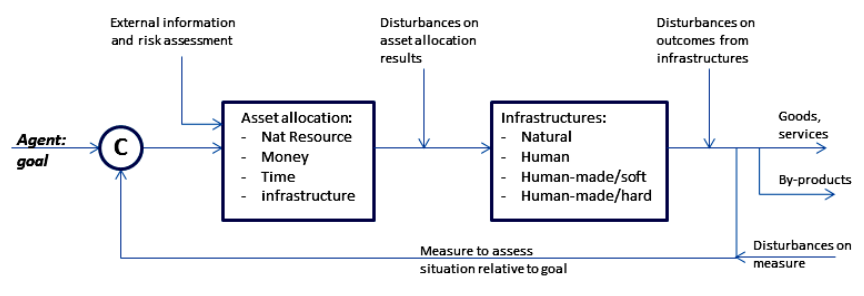

This basic representation of FBCLs can tackle multiple time scales by featuring actions that are not only allocations of assets for production of immediate flows (on the fast time scale) but also investment in infrastructures that will impact flows in future time steps (on the slow time scale) competing for limited resources in the present. This trade-off between investment and consumption is well known but does not fit well with the standard representation of a FBCL where the structure of the "plant" (or the set of infrastructures mobilized in the production process) is assumed static.

We amended Anderies's original formulation by adding and specifying disturbances and elements of knowledge (representation ${ }^{[2]}$, information, etc.) sourced out of the loop, as well as the creation of unintended by-products. Disturbances, or uncertainties (Anderies 2015), are represented by signals exogenous to the FBCL that may impact and distort signals endogenous to FBCL. Disturbances may affect outcomes of asset allocation decisions that enter the plant, outcomes from the plant, 
Fig. 2. Possible interactions between one feedback control loop (FBCL) of an agent $x$ and another FBCL of an agent $y . x=y$ is allowed but $x i \neq y j$.

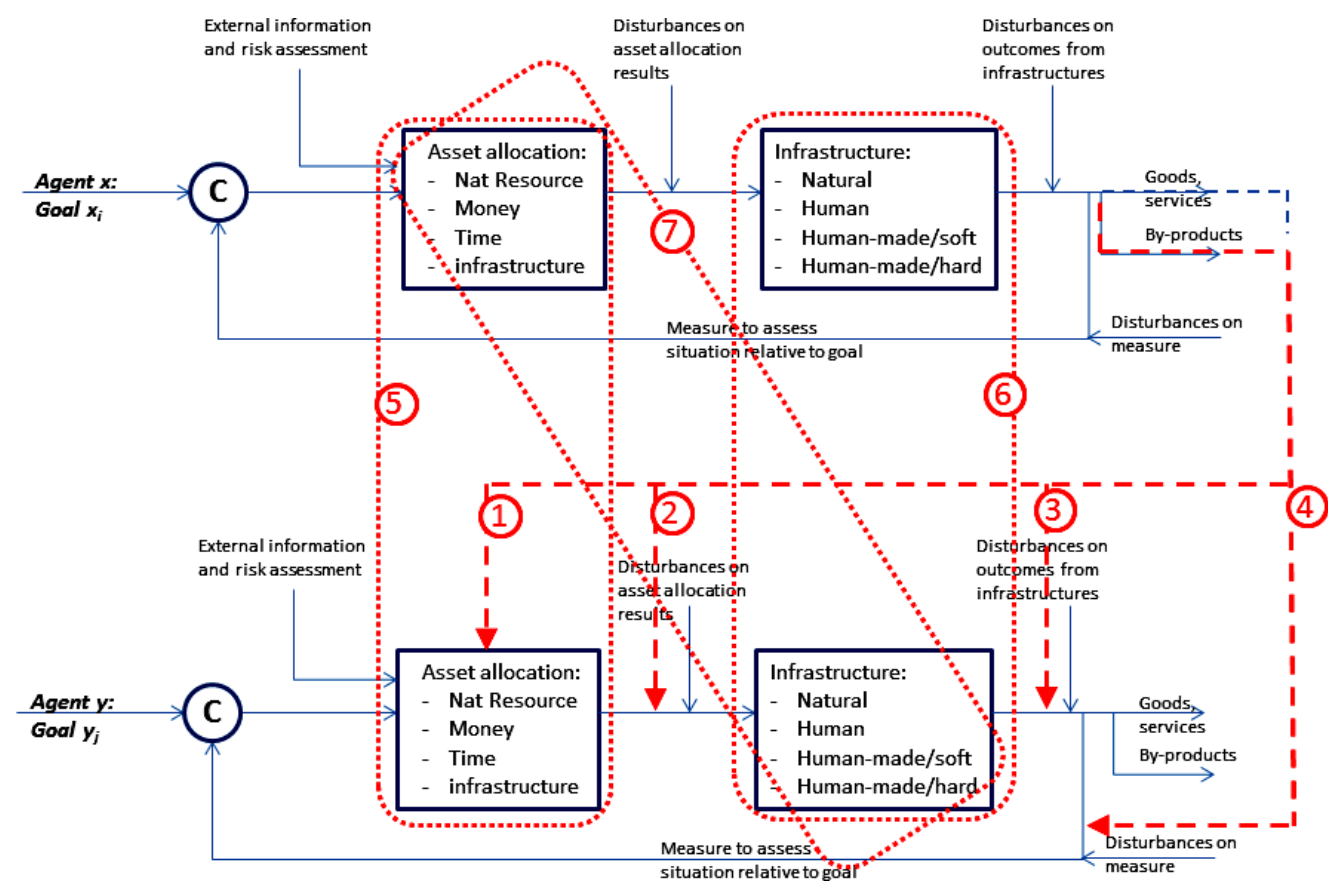

or monitoring outcomes that provide input to the controller (and subsequently measured and compared with the target, see Fig. 1). We assume agents' decisions are made based on two sources of information: (1) internal sources such as the comparison between goal and measurement to assess its level of achievement, and (2) external sources such as information on possible processes that may be employed and potential needs including risk assessment. Finally, this information may be impacted by uncertainties within the decision making unit associated with limited understanding, imperfect institutional arrangements, or biases associated with value systems such as in Anderies et al. (2019).

We now turn our attention to using networks of FBCLs as a potential method to identify interdependencies and the transfers of vulnerability they enable across a "network of adjacent action situations" (McGinnis 2011). In a similar vein, Kimmich (2013) formalized the representation of linked adjacent action situations and uncovered the underlying action situation network in the empirical example of rural electricity provision in India. The links between action situations were realized through the impact of the outcomes of a game in one action situation on payoffs (or other components) in another game in another action situation. In our case, each action situation is a FBCL operating in a dynamically varying environment rather than in a situation with fixed payoffs leading to equilibria in a game in a focal action situation. We hence extend the description of action situations as dynamic entities in order to identify vulnerabilities to exogenous drivers induced by interdependencies.

\section{Defining and analyzing vulnerability transfers}

Beyond flows of material or information, the outputs from FBCLs have the potential to become disturbances for other loops.
Assets and infrastructures involved in FBCLs might also be shared. Figure 2 shows a minimal network of FBCLs with two nodes and the theoretically possible interdependencies. All elements shown in dashed lines are intended to convey possible transfers as detailed in Table 1 .

Possible transfers are then of two major types: elements 1-4 depending on flows inducing disturbances (positive or negative) and elements 5-7 depending on sharing scarce resources or shared infrastructures. The first category is mainly related to by-products generated by one FBCL that may be exchanged with another. The second category is related to shared infrastructures and resources, with issues such as competition or mutual investment.

Based on the typology of possible vulnerability transfers listed in Table 1, we now determine whether each type can be found in real case studies. The classification in Table 1 is meant to serve as a guide in the analysis of real case studies to identify significant transfers. Within an SES featuring explicit adaptation processes, the first step is to identify the agents involved and their goals. For each association of agent and goal, the second step involves describing its adaptation process as a FBCL:

1. External pieces of information, including risk assessment, that determine an agent's set of actions;

2. Assets an agent can mobilize to progress toward her goal;

3. Infrastructures involved in the process and key uncertainties regarding their function and potential exogenous shocks;

4. Outputs, goods, and services, as well as by-products generated;

5. Process output measures used to assess whether the current pattern of action is suitable. 
The third step consists of identifying FBCLs that might affect other FBCLs through one or more of the types of transfer listed in Table 1.

Table 1. Types of vulnerability transfer mechanisms. Legend:

1. Goal to comparison circle: information about a goal, i.e., numbers specifying allowable levels of extraction, desired levels of well being, etc., quality of an infrastructure, etc.

2. Comparison circle: information about the difference between measured quantities (information flows out of a sensing device, including a human) and goal. This "error" signal enters the decision box.

3. Asset allocation to infrastructures: actions affecting infrastructure: construct, extract, change, destroy, etc.

Exiting infrastructures: state of the system (information that can be gathered by a sensor), which is fed back into the system (see point 2). Other entering arrows represent disturbances. FBCL, feedback control loop.

\begin{tabular}{|c|c|c|}
\hline ype & & Meaning \\
\hline 1 & rmation & ion \\
\hline 2 & $\begin{array}{l}\text { Impact on realized asset } \\
\text { allocation }\end{array}$ & $\begin{array}{l}\text { Assets that Agent y intended to } \\
\text { allocate are modified because of } \\
\text { FBCL } x\end{array}$ \\
\hline 3 & realized outcomes & $\begin{array}{l}\text { The outcome of processing assets } \\
\text { allocated by Agent } y \text { is perturbed } \\
\text { by FBCL } x\end{array}$ \\
\hline 4 & Impa & $\begin{array}{l}\text { toring set up by agent } y \\
\text { t she assumes because } \\
x\end{array}$ \\
\hline 5 & $\begin{array}{l}\text { Inter } \\
\text { alloc }\end{array}$ & $\begin{array}{l}\text { Availab } \\
\text { FBCLs }\end{array}$ \\
\hline 6 & $\begin{array}{l}\text { Approximation of significant } \\
\text { shared plant dynamics by agents }\end{array}$ & $\begin{array}{l}\text { Both FBCLs refer to at least one } \\
\text { common infrastructure }\end{array}$ \\
\hline 7 & $\begin{array}{l}\text { Modification of the availability } \\
\text { of main plant dynamics for } \\
\text { Agent } x \text { through its allocation to } \\
\text { other processes by Agent } y\end{array}$ & $\begin{array}{l}\text { An infrastructure mobilized, } \\
\text { hence potentially transformed, in } \\
\text { FBCL y is an asset that might be } \\
\text { used in FBCL } x\end{array}$ \\
\hline
\end{tabular}

As a demonstration of feasibility, we selected a few FBCLs for which there is evidence of a case of vulnerability transfer. Subjectivity of the analysis is handled through the use of empirical narratives produced by a field analyst (one of the coauthors of the paper) and interpreted in a minimal network of FBCLs by another member of the research team (first author) through a diagram as in Figure 2. The generated representation is assessed by the author of the narrative, and jointly revised if necessary.

\section{EMPIRICAL EVIDENCE OF POSSIBLE TYPES OF VULNERABILITY TRANSFERS}

We analyzed multiscale adaptation processes to global changes across three coastal case studies: Garden Route in South Africa, Cornwall in the UK, and Languedoc in France. Extensive fieldwork with semidirected interviews and public documentation analysis was conducted in these case studies. More information is available in reports and field based papers (Brown et al. 2017, Guerbois et al. 2019, Naylor et al. 2019, Therville et al. 2019). We use this set of case studies to identify example cases of each theoretical type of transfer of vulnerability. We select here five such example cases in order to demonstrate the diversity of existing transfers.
Asset valuation in prioritizing protection policies in the UK: bias toward large settlements

Our first example illustrates a vulnerability transfer between FBCLs featuring goals with different governance levels and reference areas. In this example case, government vulnerability to policy hazard is transferred to municipality vulnerability to hydro-meteorological hazards. Vulnerability to hydro-meteorological hazards is also transferred between municipalities.

Because flood protection policies are expensive, local communities typically need subsidies. In Cornwall, municipalities expect contributions from the national government in addition to their own match funding. However, the national government and the Environment Agency only have limited funds so must decide what to protect. The issue is then trade-offs made by the national government in allocating these limited funds. The national government has developed a partnership-funding calculator that incorporates various values into assessments of viabilities of flood schemes, including relative deprivation of areas with the aim of ensuring distributional fairness of flood protection investment. These choices require explicit justification provided by the financial valuation of assets protected. The evaluation process is conducted through a formula designed at the national level in the UK and filled in by the Environment Agency and local government (Cornwall Council) to justify the development of flood protection schemes. The outcome of these evaluation processes depends on capacity of local government to provide a value largely based on current land uses. In addition to difficulties in assessing and accounting for aesthetic and cultural values, this pattern is inherently biased against small and inland rural municipalities because low population density means that the number of properties within such communities is not large and they are also likely to be relatively cheaper than in-demand coastal view properties. In addition, it places limited value on agricultural land and buildings relative to residential properties. Hence governmental trade-offs can be largely determined by real estate market dynamics.

This issue involves two independent FBCLs, as illustrated in Figure 3. Even though both government levels are concerned with citizen protection, the national government enforces a strategy of protecting national assets targeting the highest value through accounting methods, while local councils are more concerned with the viability of towns and local culture. In the first FBCL, the national government considers its own representation of current dominant risks for each region and the values at stake. They assess the highest values that require protection in order to allocate money and expertise according to their asset valuation protocol in the light of existing infrastructures such as structural protections, e.g., dikes. The government assesses its choices according to estimated social and economic costs and benefits (with significant reference to collective value of house prices). In the second FBCL, regional municipalities have their representation of the dominant risks to people and asset values at stake. They can apply for funding from the central government for flood and coastal erosion infrastructure, and are in charge of works for local flood risk on small watercourses. These two FBCLs are connected in three ways:

1. Type 2. Through funding contributions from the national government agency to selected municipalities $(\# 1)^{[3]}$. 
Fig. 3. Vulnerability transfers observed in the UK's flood protection policies.

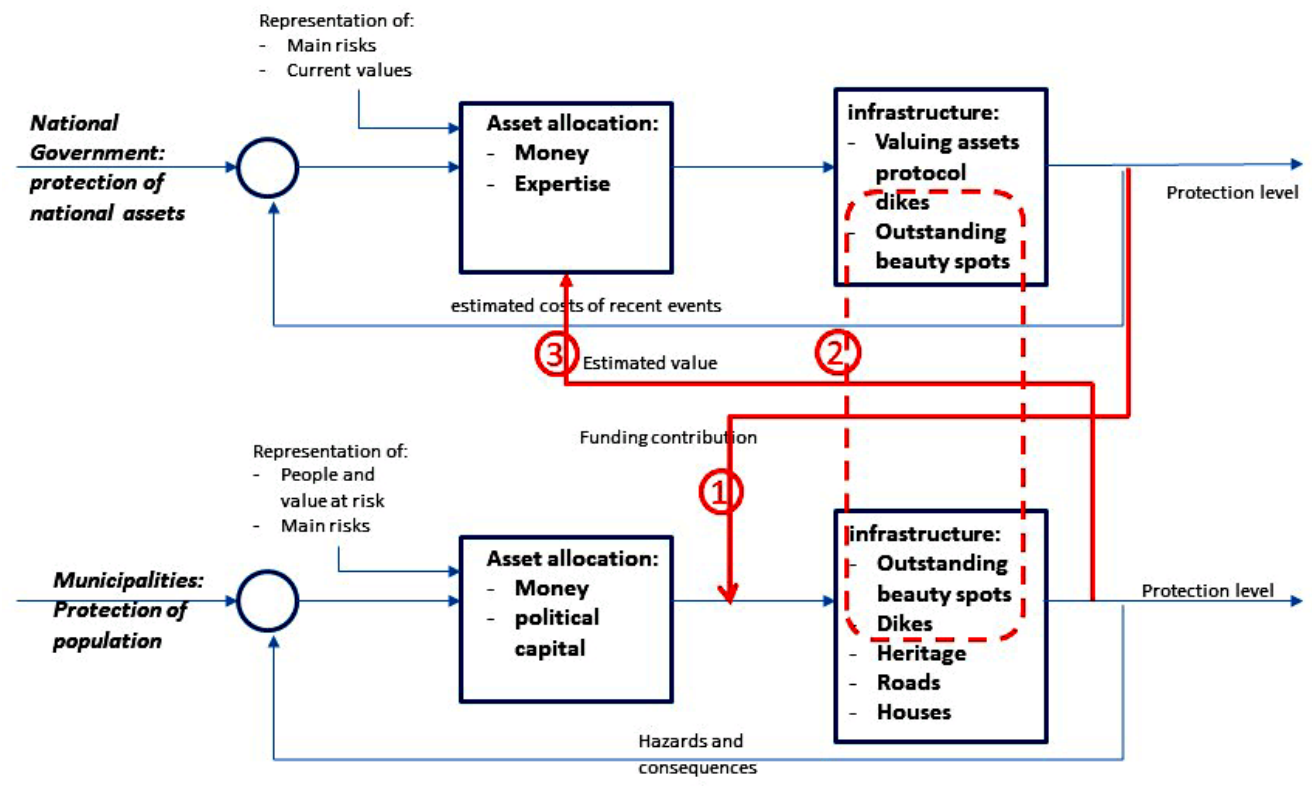

2. Type 6. Both FBCLs refer to common infrastructures: municipalities may benefit from supra-scale flood protection assets or a well-established label of interest leading to additional subsidies (\#2).

3. Type 1. Municipalities' choices are modifying the range of estimated values in partnership funding accounting process (\#3).

Municipalities transfer vulnerability to hydro-climatical hazards among themselves, as framed by government control and its own vulnerability to policy hazards. The transfer of vulnerability is down and out from central government to regional and rural government and communities. In this example the unintended consequence of a flood risk management processes is the generation of a bias against small sized settlements and communities with financially low value buildings, e.g., rural settlements.

\section{Breaching the mouth of the Wilderness Lakes Estuary in the Garden Route, South Africa}

This example illustrates a vulnerability transfer between FBCLs featuring goals with different time scales. It transfers residents' vulnerability to flooding to South African National Parks (SANParks) vulnerability to ecological degradation, through municipality vulnerability to decrease in political support.

The Wilderness Lakes area is a section of the Garden Route National Park, with portions proclaimed as Ramsar site in 1991. These wetlands, managed by SANParks, a government body dedicated to nature conservation nation-wide, are also very attractive for the leisure activities they offer, drawing large numbers of tourists and wealthy second home-owners. Global changes manifest there in increased severity of drought, flood storms, fire events, increasing human population, needs for development, and eroding ecological infrastructures (Guerbois et al. 2019). These provide the context for multiple adaptations.
The development of the flood plains and edges of the rivers and lakes as a result of the attractiveness of the estuaries and the need to increase municipality incomes has increased exposure to flooding. As part of the Garden Route National Park, flood risk in these estuaries have been managed by a nation-wide organization dedicated to nature conservation, the South African National Parks (SANParks). SANParks intervenes on the dredging of the estuaries through the breaching of the river mouths when predetermined water levels based on biophysical studies are reached. However, using their political power, influential residents along the edge of the estuaries lobbied through municipalities for the mouths to be breached earlier. Breaching the mouth too early accelerates the siltation process in the long run by decreasing the river capacity to naturally flush and move. Hence, by preventing natural flushing facilitated by high water volume in those estuaries, this adaptation has increased flood risk in the long term, while also impacting the integrity and the functionality of these unique ecosystems.

This issue involves three agents characterized by three FBCLs as illustrated in Figure 4. The mandate of the conservation organization SANParks is to ensure coastal ecosystem conservation by allowing natural processes of silting and flushing to take place, without compromising private and public infrastructures along the edge of the rivers. SANParks allocates money and labor to act on the river mouth according to a scientifically established river-mouth management protocol. The scenic beauty of the estuaries constitutes important assets for the municipalities for generating revenues through ratepayers and exploitation taxes. In the meantime, municipalities have the mandate to manage flood risk. Riverside residents and other users care for the short-term protection of their safety and assets. Their flood risk assessment is subjective and influenced by the information accessible to them. They can use their political capital when they consider their exposure to be too high and request the 
Fig. 4. Vulnerability transfers observed in estuary breaching in South Africa.

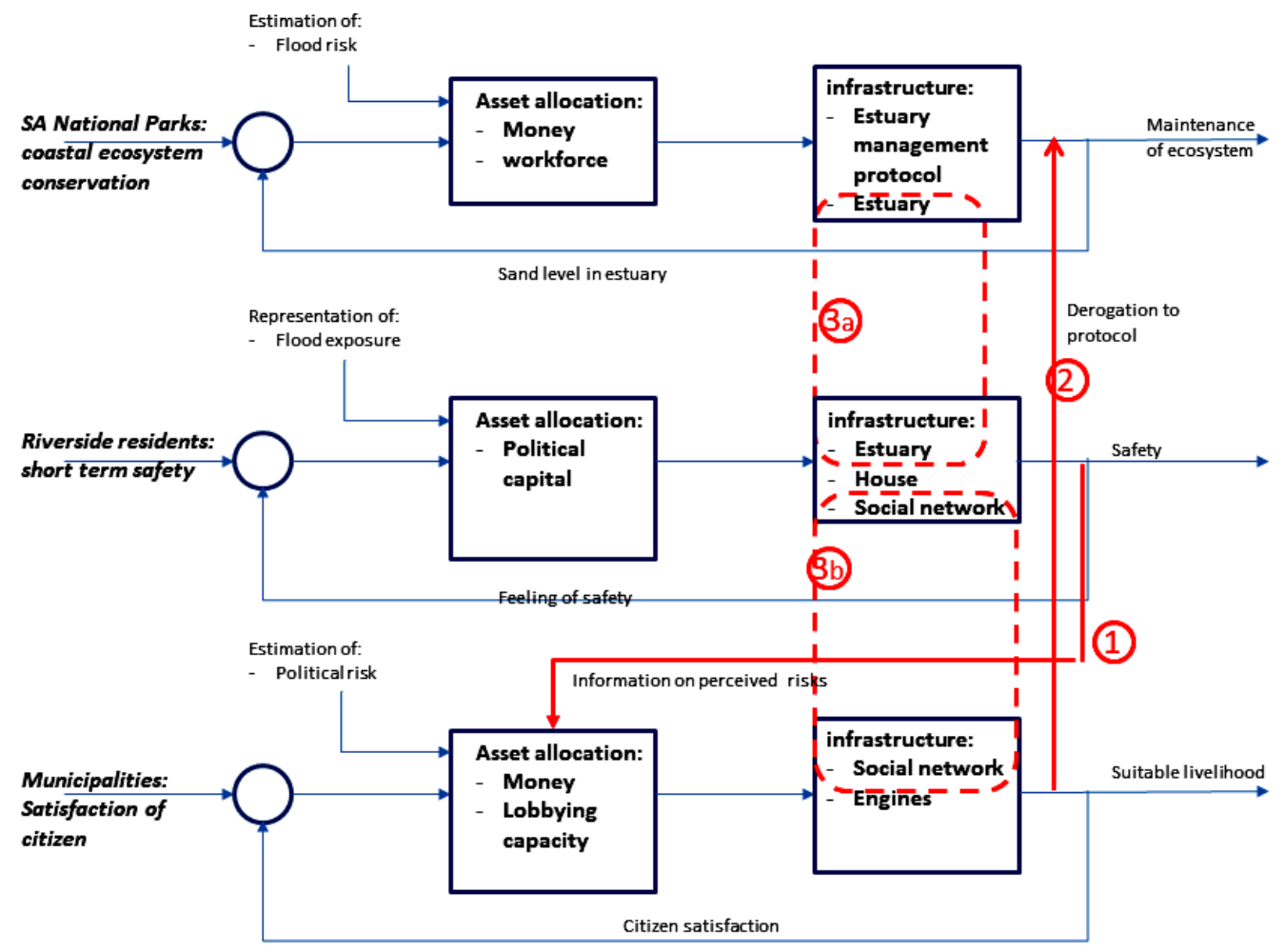

dredging of the river mouth. When successful they get a feeling of safety in the short term. The municipality is seen here as a public infrastructure provider, tied up with social and economic mandates. They mobilize their financial capacities, lobbying in social networks, and equipment to provide public services that contribute to the livelihoods of residents. These FBCLs interact in three ways:

1. Type 1 . The riverside residents can influence municipalities' estimate of political and economic risk (\#1).

2. Type 3. Municipalities' choices modify the conservation outcomes of SANParks regarding estuary dynamics through derogation to the river mouth management protocol (\#2).

3. Type 6. Sharing natural (\#3a - the river mouth) and human (\#3b-social networks) infrastructures provides some means of control for riverside residents.

Shared infrastructures (ecological infrastructures and social infrastructure) are here providing a pathway for one agent to control the interdependence characterizing the bargain between vulnerability of SANParks to ecological degradation and vulnerability of riverside residents to flooding, with an immediate reduction of vulnerability of municipalities to political risks.

Beach maintenance in the Languedoc region in France This example illustrates vulnerability transfers between FBCLs featuring goals with different domains of interest. It transfers county vulnerability to decrease of beach supply to Conservatoire du Littoral (French national coastal conservation agency) vulnerability to coastal erosion.

One of the very topical issues faced in the Languedoc region in France is coastal erosion. It is high on the political agenda at the regional level and is supported by economic stakeholders for recreational activities and mass beach tourism, but also by environmental stakeholders for biodiversity conservation values. Indeed coastal erosion is wiping out beaches, which is neither good for tourism (and hence regional economy) nor for sand dune ecosystems and associated wetlands. In order to support the tourism industry, local authorities direct significant financial resources to counter erosion through adding sand taken from the seabed or from accretion areas, and setting rock traps.

Two FBCL are involved as illustrated in Figure 5: the county authorities whose objective is beach maintenance, and the Conservatoire du Littoral whose objective is dune ecosystem conservation. According to both its assessment of beach area needed and capacity to act and the monitoring of beach size, the county allocates financial assets, labor, and sand resources to replenish the beach and/or build rock traps. Besides maintaining beach size, this practice raises uncertainties regarding degradation of marine bed ecosystems as well as disturbance of natural sand circulation. The Conservatoire du Littoral uses knowledge about dune ecosystem dynamics to add infrastructures that regulate human access, e.g., fences, wooden pathways, new access, and land use rules, etc., onto the natural infrastructure of existing dunes. The level of dune ecosystem health generated by these accessibility management infrastructures depends on actual storm events. These two FBCLs interact mainly in three ways: 
Fig. 5. Vulnerability transfers observed in beach maintenance in France.

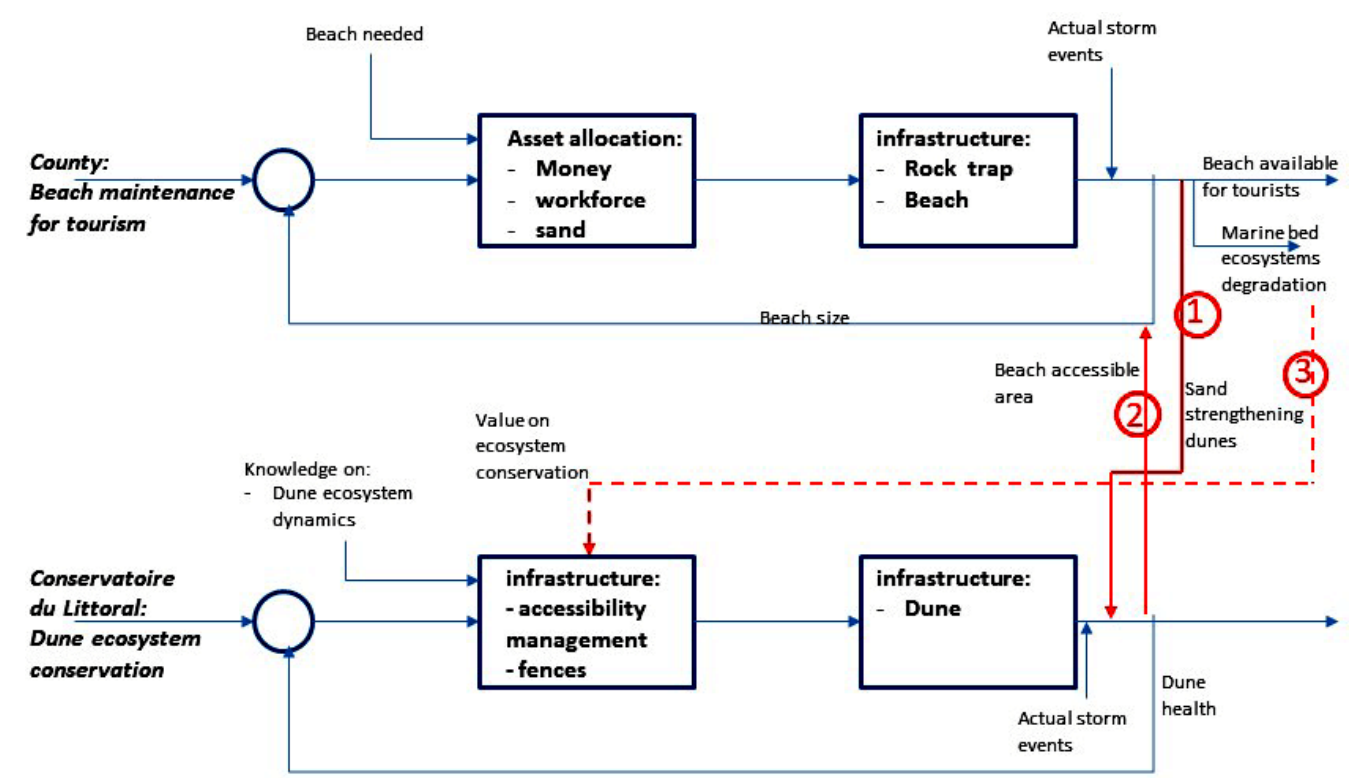

1. Type 3. Beach recharge adds sand and hence protects the dunes from erosive forces from the sea, potentially reinforcing the outcome of Conservatoire du Littoral actions in the short run (\#1).

2. Type 4. Access regulation infrastructures restrict beach area open for tourists, hence reducing the county's accessible "beach size" monitoring indicator (\#2).

3. Type 1. Sand mining degrades seabed ecosystems reducing Conservatoire du Littoral's capacity to cope with its overarching value on ecosystem conservation (\#3).

These three interactions transfer current county vulnerability, i.e., decrease of revenues from beach tourism, to the future vulnerability of Conservatoire du Littoral, i.e., seabed ecosystems degradation. This example illustrates a long-term maladaptation: adding sand to the beach reduces the perception of beach erosion, and thus long-term adaptive capacity of users, and relies on a finite resource whose extraction threatens another ecosystem, i.e., from the sand dune ecosystem to the sea bed ecosystem.

\section{Solar energy development in South Africa}

This example illustrates a vulnerability transfer between FBCLs featuring goals with different governance levels. In this case, vulnerability to energy shortages is transferred from wealthy residents to local government.

In South Africa, the government is facing the crucial challenge of providing electricity to all. Eskom, a national electricity public utility, is implementing frequent load shedding all over the country because of lack of production capacity. This calls for investments in energy infrastructure, which may generate an increase in prices for those who are already connected to local power grids in a context of high revenue inequality. Local governments are concerned that many people, mostly among the wealthy, invest in solar panels and become autonomous, off-the-grid. These disconnections decrease the ability of the government to expand the existing energy grid and provide electricity to all.

As shown in Figure 6, this example features two FBCLs. Local government drives the first loop with a goal of providing electricity to all, managing electricity as a public infrastructure system. Wealthy residents drive the second loop with a goal of securing access to electricity at a reasonable and foreseeable price. The local government takes into account the ratio of households connected to the grid as a feedback on their goal achievement. This feedback, together with their representation of future demand for electricity is used to decide on the allocation of their dedicated financial resources to expand the electricity grid. At the same time, wealthy residents decide on the basis of their electricity bill, perceived quality of service, and with their representation of reliability and costs of alternative sources to allocate their financial resources to either individual solar panels or fee payment for using the grid. These FBCLs interact in three ways:

1. Type 2. Increasing the means for grid maintenance and extension (\#1).

2. Type 5. Splitting financial resources between that dedicated to individuals' energy budgets and connection to a common electricity grid (\#2).

3. Type 6. Encouraging wealthy residents to disconnect from the local grid (\#3).

This example concerns the consequence of lack of reliable and equitable energy provision public service. It features the loss of potential for robustness transfer due to the disappearance of interdependencies between agents' FBCLs: wealthy residents' robustness to economic downturn used to be transferred to local government robustness to peak of electricity demand, which is not any longer the case. 
Fig. 6. Vulnerability transfers observed in solar energy development in South Africa.

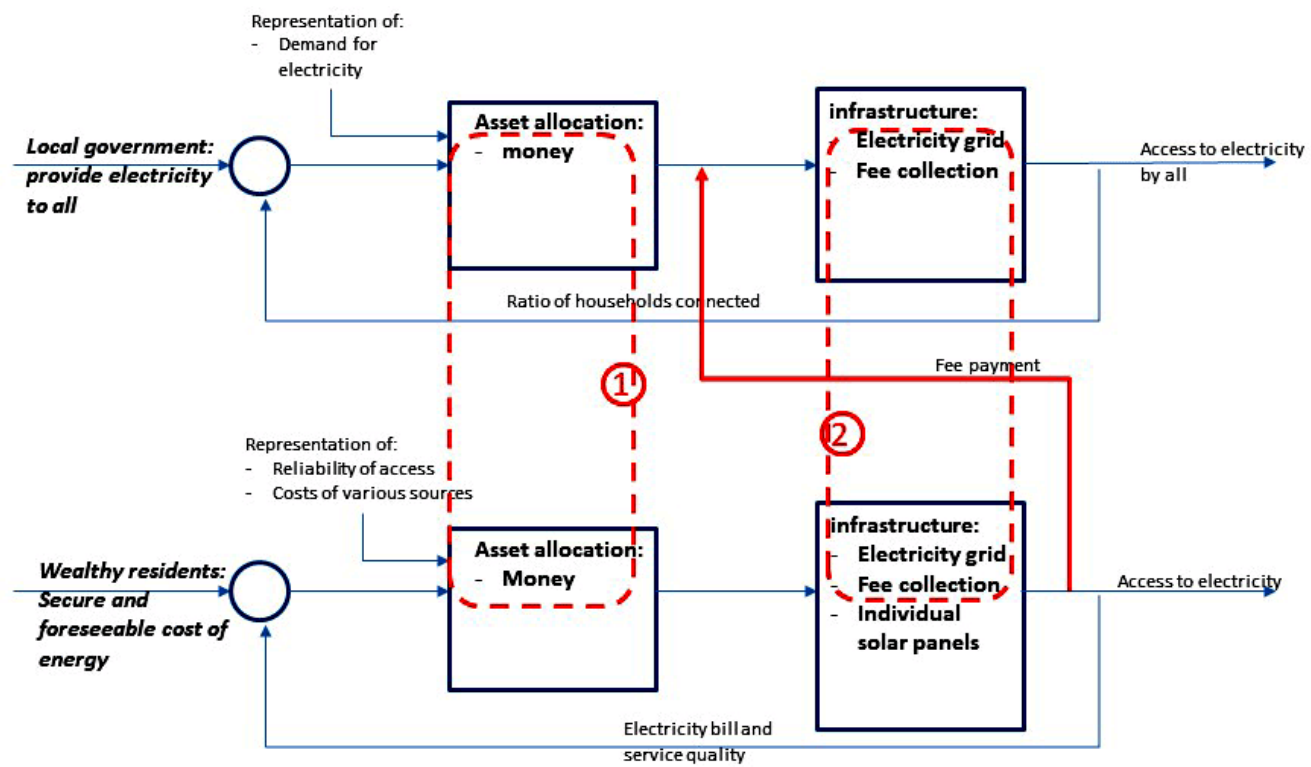

\section{Mosquito control versus biodiversity conservation in the Languedoc Region in France}

This example illustrates a vulnerability transfer between FBCLs featuring goals with different reference areas and time scales. It transfers local planning authority vulnerability to mosquito nuisance to conservation agency vulnerability to loss of biodiversity.

Another issue specific to the French case study is related to mosquito control and its consequences on biodiversity. With climate change and increasing international exchange of goods, new species of mosquitoes have appeared in southern France. They are active in cities and are increasing the sensitivity of urban populations to potential vectors of serious disease and the general nuisance of biting insects.

Mosquitoes have always been present in regional coastal wetlands, managed in some places to suit tourism, and left in other places in order to maintain ecological processes, i.e., especially to conserve insect-eating migratory birds, or indirectly to discourage tourism-focused development. Economic interests pushing for increased tourism and sensitivity of urban populations to mosquitoes are putting this issue back on the political agenda. The discovery of new low impact bioinsecticide, e.g., the Bacillus thuringiensis israelensis or Bti) to control mosquitoes has also led to reconsideration of the issue leading local planning authorities to take a tougher stance on mosquito nuisance reduction.

Two FBCLs are active, as illustrated in Figure 7. Local planning authorities aim to reduce the mosquito nuisance while the Coastal Conservation Agency and environmental NGOs (represented together in Figure 7) care for biodiversity conservation. The local planning authorities estimate impacts of available molecules and the risk of mosquito spread in association with the perceived nuisance of mosquitoes. Local planning authorities use financial capacity and their political power to set rules regarding land uses and to activate human-made infrastructure such as a "Bti spreading platform." They take part in the management of a natural infrastructure, the lagoons, and associated wetlands, in order to regulate the mosquito population and increase the quality of tourists' and urban inhabitants' experience. On the other hand, the Coastal Conservation Agency and environmental NGOs (and scientists) focus on the extent of the impacts of this biopesticide on wetlands and its fauna, especially by monitoring bird populations. They allocate their funding capacity, social capital, and conservation tools with the intention to control the ecological state of wetlands with land use and water management rules. They try to influence the state representative regarding authorization of specific pesticide spreading. These FBCLs interact in three ways:

1. Type 2. The dispersion of Bti into the trophic chain impacts the efficiency of allocation of conservation tools through the natural infrastructure (\#1).

2. Type 6. Both FBCLs share an infrastructure, the lagoon and associated wetlands. The way they use it modifies its state and regulation (\#2).

3. Type 7. Rules related to access and use of wetlands are part of the infrastructure landscape of action in the second FBCL while they are part of the assets activated by the local planning authority in their effort to regulate mosquito nuisance. Their modification by the Coastal Conservation Agency change local planning authorities' capacity to act (\#3).

Vulnerability of local planning authority to mosquito threat in the short term is decreased at the expense of an increase of vulnerability of Conservatoire du Littoral to a rarefaction of some bird and other insect populations in the long term. The relative power of both institutions is setting the balance between both vulnerabilities. This example questions the prevailing viewpoint about "adaptation to what and for whom" when 
Fig. 7. Vulnerability transfers observed in mosquito control in France. Bti, Bacillus thuringiensis israelensis.

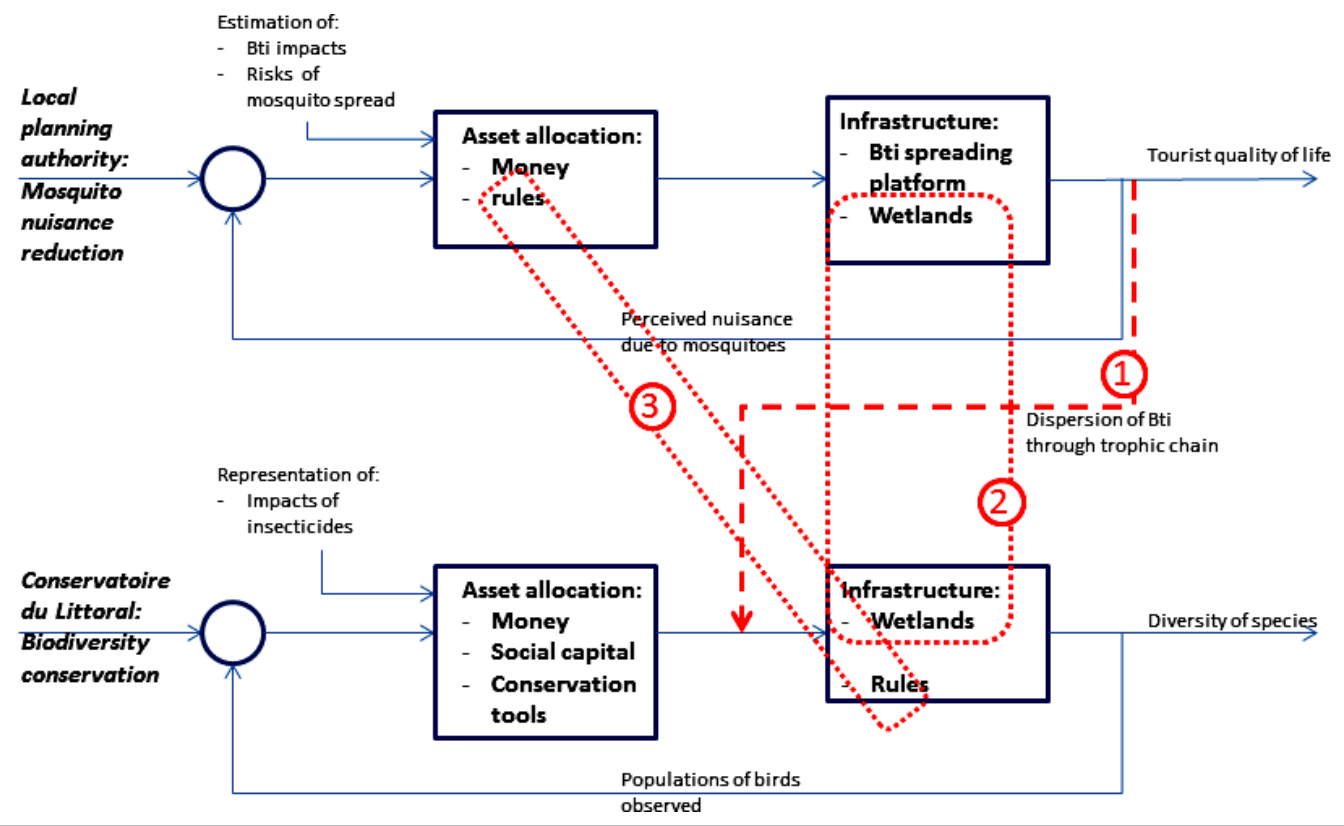

multiple agents share an infrastructure: expanding the use of Bti seems an adequate adaptation to a greater mosquito nuisance by local planning authorities but generates unintended impacts on biodiversity through food web interactions in wetlands (Poulin et al. 2010).

\section{DISCUSSION}

The insights from example cases in the previous section illustrates the capacity of the network of the FBCL framework to help characterize transfers of vulnerability. In this section, we build on these empirical examples and discuss the capacity of the network of the FBCL framework to encompass the existing concepts described above. We discuss the relative frequencies of various types of mechanism we identified in the empirical example cases. We then return to the potential added value of the framework and, finally, explore some consequences from a political ecology perspective.

\section{Usefulness of network of FBCL framework for exploring interdependency effects}

The network of the FBCL framework integrates previously developed concepts to deal with various interdependencies including spillovers and CPRs. It provides a compact representation suitable to describe vulnerability transfers. It is made up of seven types of transfer identified first through a theoretical analysis. It provides a description of the mechanisms enabling transfers while previous conceptual frameworks largely focus on qualifying the consequences of transfers. Although previous studies have revealed the damages caused by actions of one agent that impact another ex-post, this formalism paves the way for ex-ante structured discussions about potential transfers, which is still to be tested.

The five example cases above feature all seven types of interactions listed in Table 1. This demonstrates that all the theoretically possible mechanisms for vulnerability transfer can be observed in practice. Our case studies in South Africa, the UK, and France feature nine more examples of interactions in addition to the five we selected for this paper. With the same method based on interview and validation between one analyst and one case study leader, we identified and described a total of 14 example cases of vulnerability transfers among the three case studies. They are not representative, but we consider they may already enable the identification of some trends:

1. Infrastructure sharing occurs in most example cases (10/14), while other links are less frequent;

2. Interdependencies due to generated flows (8/14), which are also well analyzed in the literature, come second to infrastructure sharing.

3. The competition for resources that is the focus of the extensive literature on commons is not the main interdependency involved in vulnerability transfer (only 2/14);

The benefit of the network of the FBCLs approach is that it provides a systematic way for clarifying interdependencies and possible vulnerability transfers between adaptation actors. It is based upon the identification of the generated flows as well as intersections between asset allocation decision making and/or significant infrastructures. The transfers we can describe as flows (types 1, 2, 3, and 4) affect exposure and sensitivity, while those we can describe as due to shared resources (type 5) or infrastructures (type 6) relate largely to adaptive capacity.

With its strong focus on the systemic nature of SES, this framework could lead, in theory, to an exhaustive identification of potential vulnerability transfers provided that the work of describing networks of FBCLs is exhaustive in the investigated SES. This last condition is obviously not an easy one. First, 
application to an entire SES would be cumbersome because of the potentially very large number of FBCLs. It is the analyst's responsibility to identify the crucial ones: those that involve the main dynamics, the most sensitive goals, as well as those that involve the weakest agents. Second, weak agents, those who might suffer from transfers, tend to go unnoticed. There is still a need for a capacity to give these weak agents voice in suitable policy arenas to identify the FBCLs they are involved in. Highlighting how weak agents are connected in FBCLs is one approach to help prevent default silent acceptance of vulnerability transfers.

Identification of main potential vulnerability transfers may help practitioners together with scholars to delineate who should be part of a collective action arena meant to coordinate adaptation actions and improve their efficiency at system level. We consider extension of network of FBCLs as a proxy to identify a pathway to handle interdependencies in adaptation patterns.

The FBCL metaphor is extremely general and applicable at all scales. However, it is important that we are careful about how we think of "control." When we think of feedback loops in terms of management and control, this assumes, in theory, that there is some sort of rational planning actor consciously controlling the system. However, in practice, decision makers are restricted by limited knowledge, limited information, and limited legitimacy and ability to act on the system. Moreover, feedbacks can emerge without conscious, forward-looking planning. Myopic actors make decisions without full knowledge of the structure of the system that can lead to the emergence of FBCL where "control" is partial and limited. Given that large infrastructure systems require planned adaptation in the face of limited information and ability to act, it is all the more important to incorporate vulnerability transfers into the planning process because of it is a source of uncertainties. Rational planning hence may call for collaboration and communication across local FBCL systems.

\section{Sharing infrastructures}

Qualitative FBCL network analysis of three case studies has highlighted infrastructure sharing as a key co-occurring interdependence, while most other approaches are restricted to flows and sequential interdependencies (Kimmich 2013). Based on the case studies presented here, the existence of significant sharing of infrastructures seems the most common interdependency through which vulnerability transfers are conveyed. Agents consider many infrastructures they mobilize as part of their decision-making context even though they do not contribute to their maintenance or preservation. For example, the pathways used by South African women to access their fishing grounds are part of a long lasting trail network that is currently managed according to the interests of the tourism industry. Any change in access to these pathways may change the capacity of fishing women to transform their effort into food.

Shared infrastructures connect FBCLs in various ways. We have found three types of interdependency to be of particular importance:

1. Agents involved in two linked FBCLs intend to use the same infrastructure for different purposes and, as a result, operate it in different ways, as with multifunctional infrastructures. Dams are classical examples, where choices must be made involving trade-offs between flood control, water supply, energy production, and recreational activities (Duflo and Pande 2007, Brown et al. 2009, McNally et al. 2009). They destabilize agreements between actors (Siciliano et al. 2015), highlighting the need to manage links between FBCLs.

2. Operation of an infrastructure by an agent $x$ modifies its quality and reduces its suitability and/or value to other users without any intention or even perception of degradation by $x$. In the mosquito example case, degradation of wetlands due to the use of Bti is not meaningful to local planning authorities, and hence not properly monitored.

3. Weak agents $X$, i.e., having few resources, benefit from an infrastructure maintained by others $Y$ without generating any loss in the service provided by it. It is still rational for $Y$ to maintain. This transfer of robustness is de facto a tacit social compromise. However when maintenance of this infrastructure is no longer needed for $Y$ or is threatening their robustness, it may be stopped and the service provided to $X$ disappears, which is endangered by changes due to decisions made outside the scope of this compromise. Free riders $X$ will suffer from an unplanned shift in the strategy of the first agent $Y$ in maintaining the shared infrastructure. This can lead to a major shock to the livelihoods of the free riders $X$. The transfer of vulnerability in this case is due to the absence of a formal agreement on joint interests in shared infrastructure, similarly to public good provision problems in the case of investment or maintenance of shared infrastructure (Ostrom et al. 1993).

\section{Clarifying missing links}

Our framework also provides a means to analyze missing links. Empowering weak agents starts with identifying infrastructures they consider meaningful as part of their own processes. Drawing the diagrams enables one to identify links that could be added to generate win/win transfers and generate solidarity. In the French case study, another example case features interdependencies between two FBCLs concerned with flood issues. It highlights that for residents, public places and professional buildings are meaningful infrastructures to achieve their goal of seeking security, while the municipality is rather focusing on land use zoning and individual mitigation plans. Without an actual link between both FBCLs, the municipality is paying no attention to residents' key infrastructures.

Hence, although it is possible with our framework to account for various conceptualizations of spillovers and externalities, it also facilitates explicit, systematic study of how vulnerabilities can cascade across a system because of unintended consequences of governance regimes. Our identification of seven types of vulnerability transfer mechanism as a complete and relevant typology provides for an ex-ante capacity to identify and negotiate how the costs (impacts) of vulnerabilities are borne across space, time, and social groups. Given the possibility of vulnerability transfers we have outlined, the current situation with the proliferation of uncoordinated adaptation plans mentioned in the introduction could be a significant problem. Our analysis suggests that a thorough analysis of potential transfers provided by adaptation plans under construction may bring relevant links to the fore, and could be used to prepare for the more effective negotiation of agreements to promote coordination between connected FBCLs. 


\section{Consequences of autonomous loops}

Political ecology considers adaptation as a social process (Basset and Fogelman 2013). It is consistent with our framework because it fits an aggregated view of what is emerging from interactions among multiple autonomous adapting FBCLs. Adaptation could hence lead to the exertion of authority (Eriksen et al. 2015), either through controlling other agents' FBCLs or imposing its own FBCLs regardless of the consequences for others. Interdependencies among FBCLs show that power relation analysis could be conducted with the identification of intersections between FBCLs and resulting in possible win-win solutions or double binding situations.

The issue now is to deal with these vulnerability transfers in order to prevent local adaptations from generating maladaptations that may worsen or weaken the economic and security situation of some agents. A first attempt could involve the integration of FBCL analysis with the identification or emergence of a supraagent that would provide the best adaptation pattern for all agents. This is a tentative solution, relying on governmental institutions, to prevent coordination difficulties in local public goods management due to individual rent maximizing behaviors (Osberghaus et al. 2010). However, total system optimization is a very difficult task, if ever feasible, and could lead to apparent consensus, i.e., as a consultation process without collective decision (Lascoumes and Le Gallès 2005). As Osberghaus and colleagues (2010) propose, a polycentric approach might help. From a policy making point of view, FBCL analysis enables us to move beyond the issue of choosing a unique (complex) social goal and finding the elusive set of controls to achieve it. Instead, it provides means for the identification of interdependencies that require coordination from a polycentric view perspective. This identification points out then where effort toward negotiation support should be delivered. Dialogue based on FBCL analysis might hence help to circumvent barriers to adaptation due to collective action obstacles as those pointed out by Oberlack and Eisenack (2018).

Hence, we conclude that a critical need is to provide suitable arenas for this coordination and negotiation to occur. This goes in the same direction as the conclusions by Alexander et al. (2015) regarding the need for comanagement: social network analysis could enhance comanagement by coupling FBCLs more strongly. Preidentifying possible vulnerability transfers facilitates the implementation of institutional solutions to environmental problems, because it anchors adaptation actors and their interdependencies in their context, as recommended by Paavola and Adger (2005).

\section{CONCLUSION AND OUTLOOK}

Our empirical investigation shows that all theoretically possible links between FBCLs generated by autonomous adaptation agents in a common SES may be observed. Representation of vulnerability transfers through a network of distributed interdependent FBCLs enabled us to predetermine types of interdependencies among adaptation actors that could lead to vulnerability transfers. We could spot occurrences of each type in case studies. Further study of empirical examples is needed to identify potential correlations between types of transfer and distance between FBCLs.

The approach we developed entails identifying ex-ante all flows of vulnerability, including invisible or nonmaterial ones. Pre- existing concepts meant to capture ex-post interdependencies focus on consequential interdependencies, missing, for example, shared infrastructures. Our work emphasizes the need to track pathways caused by potential flows of vulnerability, and provides some preliminary tools for doing so.

The existence of interdependence does not mean there is an actual vulnerability transfer; nor does it mean that it should necessarily be prevented. Rather, after identifying possible interdependencies, we need to strive to understand the scope of possible transfers this interdependence may convey. We observe that transfers mostly shift vulnerability from one agent to another. Hence, it is difficult to conduct an integrated quantitative analysis of change of a general vulnerability. However, in most example cases a decrease of vulnerability for one agent generates an increase of vulnerability for another. This is due to the inefficiency of distributed loci for adaptation decisions. Conversely, we also observe, less frequently, transfers with an overall decrease of vulnerability: difference of goals can lead to a more efficient distribution of exposure or a reinforcement of adaptive capacity when possibilities of transfer are identified, e.g., Conservatoire du Littoral and county authorities at beach level with sand recharge. These potential opportunities also need an arena in which to gather concerned agents to build on these win-win situations. In any event, discussion with stakeholders of types of transfers and their expected consequences is required. SES level participatory approaches could structure these discussions, and enable the joint exploration of the potential for ecological solidarity (Mathevet et al. 2018a) at SES scale.

${ }^{[1]}$ https://www.ipcc.ch/site/assets/uploads/2018/03/wg2TARannexB. pdf

[2] All across this paper "representation" accounts for the way people view their environment.

${ }^{[3]}$ For each case example described here, $(\# \mathrm{i})$ refers to a link in the current figure marked with the same "i" in a circle, with $i$ belonging to $\{1 ; 2 ; 3 ; 3 \mathrm{a} ; 3 \mathrm{~b}\}$.

Responses to this article can be read online at: http://www.ecologyandsociety.org/issues/responses. php/11402

\section{Acknowledgments:}

This work was supported by the French ANR, the US NSF, the British NERC, and South Africa NRF, through Belmont Forum Coastal Vulnerability call. Other partners of the Multi-Scale Adaptation to climate change and social-ecological sustainability in coastal areas (MAGIC) project are thanked for their support in proof reading the article.

\section{LITERATURE CITED}

Adger, W. N., N. W. Arnell, and E. L. Tompkins. 2005. Successful adaptation to climate change across scales. Global Environmental Change 15(2):77-86. https://doi.org/10.1016/j.gloenvcha.2004.12.005 
Adger, W. N., H. Eakin, and A. Winkels. 2009b. Nested and teleconnected vulnerabilities to environmental change. Frontiers in Ecology and the Environment 7(3):150-157. https://doi. org/10.1890/070148

Adger, W. N., I. Lorenzoni, and K. L. O'Brien. 2009a. Adapting to climate change: thresholds, values, governance. Cambridge University Press, Cambridge, UK. https://doi.org/10.1017/ $\underline{\text { cbo9780511596667 }}$

Alexander, S. M., D. Armitage, and A. Charles. 2015. Social networks and transitions to co-management in Jamaican marine reserves and small-scale fisheries. Global Environmental Change 35:213-225. https://doi.org/10.1016/j.gloenvcha.2015.09.001

Anderies, J. M. 2015. Understanding the dynamics of sustainable social-ecological systems: human behavior, institutions, and regulatory feedback networks. Bulletin of Mathematical Biology 77(2):259-280. https://doi.org/10.1007/s11538-014-0030-Z

Anderies, J. M., J.-D. Mathias, and M. A. Janssen. 2019. Knowledge infrastructure and safe operating spaces in socialecological systems. Proceedings of the National Academy of Sciences 116(12):5277-5284. https://doi.org/10.1073/pnas.1802885115

Arthur, W. B., S. N. Durlauf, and D. A. Lane. 1997. The economy as an evolving complex system II. CRC, Boca Raton, Florida, USA. https://doi.org/10.1201/9780429496639

Atteridge, A., and E. Remling. 2018. Is adaptation reducing vulnerability or redistributing it? WIREs Climate Change 9:e500. https://doi.org/10.1002/wcc.500

Bark, R. H. 2011. Levelling the playing field- a case study of how non-market values can compete in policy debates over wastewater allocation in a semi-arid region. Policy and Society 30:311-321. https://doi.org/10.1016/j.polsoc.2011.10.002

Barnett, J., and S. O'Neill. 2010. Maladaptation. Global Environmental Change 20:211-213. https://doi.org/10.1016/j. gloenvcha.2009.11.004

Basset, T. J., and C. Fogelman. 2013. Déjà vu or something new? The adaptation concept in the climate change literature. Geoforum 48:42-53. https://doi.org/10.1016/j.geoforum.2013.04.010

Bisaro, A., and J. Hinkel. 2016. Governance of social dilemmas in climate change adaptation. Nature Climate Change 6:354-359. https://doi.org/10.1038/nclimate2936

Bousquet, F., A. Botta, L. Alinovi, O. Barreteau, D. Bossio, K. Brown, P. Caron, P. Cury, M. D'Errico, F. DeClerck, H. Dessard, E. Enfors Kautsky, C. Fabricius, C. Folke, L. Fortmann, B. Hubert, D. Magda, R. Mathevet, R. B. Norgaard, A. Quinlan, and C. Staver. 2016. Resilience and development: mobilizing for transformation. Ecology and Society 21(3):40. https://doi. org/10.5751/ES-08754-210340

Brown, K., L. A. Naylor, and T. Quinn. 2017. Making space for proactive adaptation of rapidly changing coasts: a windows of opportunity approach. Sustainability 9(8):1408. https://doi. org/10.3390/su9081408

Brown, P. H., D. Tullos, B. Tilt, D. Magee, and A. T. Wolf. 2009. Modeling the costs and benefits of dam construction from a multidisciplinary perspective. Journal of Environmental Management 90:S303-S311. https://doi.org/10.1016/j.jenvman.2008.07.025
Cannon, T., and D. Müller-Mahn. 2010. Vulnerability, resilience and development discourses in context of climate change. Natural Hazards 55:621-635. https://doi.org/10.1007/s11069-010-9499-4

Centeno, M. A., M. Nag, T. S. Patterson, A. Shaver, and A. J. Windawi. 2015. The emergence of global systemic risk. Annual Review of Sociology 41:65-85. https://doi.org/10.1146/annurevsoc-073014-112317

Challies, E., J. Newig, and A. Lenschow. 2014. What role for social-ecological systems research in governing global teleconnections? Global Environmental Change 27:32-40. https:// doi.org/10.1016/j.gloenvcha.2014.04.015

Dahlman, C. J. 1979. The problem of externality. Journal of Law and Economics 22(1):141-162. https://doi.org/10.1086/466936

Daniell, K. A., and O. Barreteau. 2014. Water governance across competing scales: coupling land and water management. Journal of Hydrology 519(C):2367-2380. https://doi.org/10.1016/j. jhydrol.2014.10.055

Duflo, E., and R. Pande. 2007. Dams. Quarterly Journal of Economics 122(2):601-646. https://doi.org/10.1162/qjec.122.2.601

Eakin, H., R. DeFries, S. Kerr, E. F. Lambin, J. Liu, P. J. Marcotullio, P. Messerli, A. Reenberg, X. Rueda, S. R. Swaffield, B. Wicke, and K. Zimmerer. 2014. Significance of telecoupling for exploration of land-use change. Pages 141-161 in K. C. Seto and and A. Reenberg, editors. Rethinking global land use in an urban era. MIT Press, Cambridge, Massachusetts, USA. https:// doi.org/10.7551/mitpress/9780262026901.003.0008

Eisenack, K. 2016. Institutional adaptation to cooling water scarcity for thermoelectric power generation under global warming. Ecological Economics 124:153-163. https://doi. org/10.1016/j.ecolecon.2016.01.016

Eisenack, K., and R. Stecker. 2012. A framework for analyzing climate change adaptations as actions. Mitigation and Adaptation Strategies for Global Change 17:243-260. https://doi.org/10.1007/ s11027-011-9323-9

Eriksen, S. H., A. J. Nightingale, and H. Eakin. 2015. Reframing adaptation: the political nature of climate change adaptation. Global Environmental Change 35:523-533. https://doi.org/10.1016/ j.gloenvcha.2015.09.014

Folke, C., S. R. Carpenter, B. Walker, M. Scheffer, T. Chapin, and J. Rockström. 2010. Resilience thinking integrating resilience, adaptability and transformability. Ecology and Society 15(4):20. https://doi.org/10.5751/ES-03610-150420

Friis, C., J. Ø. Nielsen, I. Otero, H. Haberl, J. Niewöhner, and P. Hostert. 2016. From teleconnection to telecoupling: taking stock of an emerging framework in land system science. Journal of Land Use Science 11(2):131-153. http://dx.doi.org/10.1080/1747423X.2015 .1096423

Guerbois, C., U. Brady, A. G. de Swardt, and C. Fabricius. 2019. Nurturing ecosystem-based adaptations in South Africa's Garden Route: a common pool resource governance perspective. Regional Environmental Change 19:1849-1863. https://doi. org/10.1007/s10113-019-01508-5

Guerrin, J., G. Bouleau, and F. Grelot. 2014. "Functional fit" versus "politics of scale" in the governance of floodplain retention 
capacity. Journal of Hydrology 519:2405-2414. https://doi. org/10.1016/j.jhydrol.2014.08.024

Khan, S., T. Rana, and M. A. Hanjra. 2008. A cross disciplinary framework for linking farms with regional groundwater and salinity management targets. Agricultural Water Management 95:35-47. https://doi.org/10.1016/j.agwat.2007.09.005

Kimmich, C. 2013. Linking action situations: coordination, conflicts, and evolution in electricity provision for irrigation in Andhra Pradesh, India. Ecological Economics 90:150-158. https:// doi.org/10.1016/i.ecolecon.2013.03.017

Klein, R. J. T., G. F. Midgley, B. L. Preston, M. Alam, F. G. H. Berkhout, K. Dow, and M. R. Shaw. 2014. Adaptation opportunities, constraints, and limits. Pages 899-943 in C. B. Field, V. R. Barros, D. J. Dokken, K. J. Mach, M. D. Mastrandrea, T. E. Bilir, M. Chatterjee, K. L. Ebi, Y. O. Estrada, R. C. Genova, B. Girma, E. S. Kissel, A. N. Levy, S. MacCracken, P. R. Mastrandrea, and L. L. White, editors. Climate change 2014: impacts, adaptation, and vulnerability. Part A: global and sectoral aspects. Contribution of Working Group II to the Fifth Assessment Report of the Intergovernmental Panel on Climate Change. Cambridge University Press, Cambridge, UK. https://doi. org/10.1017/cbo9781107415379.021

Kumar, M. D., and O. P. Singh. 2005. Virtual water in global food and water policy making: is there a need for rethinking? Water Resources Management 19:759-789. https://doi.org/10.1007/ s11269-005-3278-0

Lascoumes, P., and P. Le Gallès. 2005. L'action publique saisie par ses instruments. Pages 11-44 in P. Lascoumes and P. Le Gallès, editors. Gouverner par les instruments. Presses de la Fondation nationale des sciences politiques, Paris, France.

Loiseau, E., P. Roux, G. Junqua, P. Maurel, and V. Bellon-Maurel. 2013. Adapting the LCA framework to environmental assessment in land planning. International Journal of Life Cycle Assessment 18(8):1533-1548. https://doi.org/10.1007/s11367-013-0588-y

Lutter, S., S. Pfister, S. Giljum, H. Wieland, and C. Mutel. 2016. Spatially explicit assessment of water embodied in European trade: a product-level multi-regional input-output analysis. Global Environmental Change 38:171-182. https://doi.org/10.1016/ j.gloenvcha.2016.03.001

Mathevet, R., F. Bousquet, C. Larrère, and R. Larrère. $2018 a$. Environmental stewardship and ecological solidarity: rethinking social-ecological interdependency and responsibility. Journal of Agricultural and Environmental Ethics 31(5):605-623. https://doi. org/10.1007/s10806-018-9749-0

Mathevet, R., F. Bousquet, and C. M. Raymond. 2018b. The concept of stewardship in sustainability science and conservation biology. Biological Conservation 217:363-370. https://doi. org/10.1016/j.biocon.2017.10.015

Mathevet, R., J. D. Thompson, C. Folke and F. S. Chapin III. 2016. Protected areas and their surrounding territory: socioecological systems in the context of ecological solidarity. Ecological Application 26:5-16. https://doi.org/10.1890/14-0421

McGinnis, M. D. 2011. Networks of adjacent action situations in polycentric governance. Policy Studies Journal 39(1):51-78. https://doi.org/10.1111/j.1541-0072.2010.00396.x
McGinnis, M. D., and E. Ostrom. 2014. Social-ecological system framework: initial changes and continuing challenges. Ecology and Society 19(2):30. https://doi.org/10.5751/ES-06387-190230

McNally, A., D. Magee, and A. T. Wolf. 2009. Hydropower and sustainability: resilience and vulnerability in China's powersheds. Journal of Environmental Management 90:S286-S293. https://doi. org/10.1016/j.jenvman.2008.07.029

Nagendra, H., and E. Ostrom. 2012. Polycentric governance of multifunctional forested landscapes. International Journal of the Commons 6(2):104-133. https://doi.org/10.18352/ijc.321

Naylor, L. A., U. Brady, T. Quinn, K. Brown, and J. M. Anderies. 2019. A multiscale analysis of social-ecological system robustness and vulnerability in Cornwall, UK. Regional Environmental Change 19(7):1835-1848. https://doi.org/10.1007/s10113-019-01530-7

Oberlack, C. 2017. Diagnosing institutional barriers and opportunities for adaptation to climate change. Mitigation and Adaptation Strategies for Global Change 22:805-838. https://doi. org/10.1007/s11027-015-9699-Z

Oberlack, C., S. Boillat, S. Brönnimann, J.-D. Gerber, A. Heinimann, C. Ifejika Speranza, P. Messerli, S. Rist, and U. Wiesmann. 2018. Polycentric governance in telecoupled resource systems. Ecology and Society 23(1):16. https://doi.org/10.5751/ ES-09902-230116

Oberlack, C., and K. Eisenack. 2018. Archetypical barriers to adapting water governance in river basins to climate change. Journal of Institutional Economics 14(3):527-555. https://doi. org/10.1017/S1744137417000509

Osbahr, H., C. Twyman, W. N. Adger, and D. S. G. Thomas. 2010. Evaluating successful livelihood adaptation to climate variability and change in Southern Africa. Ecology and Society 15(2):27. https://doi.org/10.5751/ES-03388-150227

Osberghaus, D., A. Dannenberg, T. Mennel, and B. Sturm. 2010. The role of the government in adaptation to climate change. Environment and Planning C: Politics and Space 28:834-850. https://doi.org/10.1068/c09179j

Ostrom, E. 1990. Governing the commons: the evolutions of institutions for collective action. Cambridge University Press, Cambridge, UK.

Ostrom, E. 1999. Coping with tragedies of the commons. Annual Review of Political Science 2:493-535. https://doi.org/10.1146/ annurev.polisci.2.1.493

Ostrom, E. 2005. Understanding institutional diversity Princeton University Press, Princeton, New Jersey, USA.

Ostrom, E., L. Schroeder, and S. Wynne. 1993. Institutional incentives and sustainable development: infrastructure policies in perspective Westview, Boulder, Colorado, USA.

Paavola, J., and W. N. Adger. 2005. Institutional ecological economics. Ecological Economics 53:353-368. https://doi. org/10.1016/j.ecolecon.2004.09.017

Pascual, U., I. Palomo, W. M. Adams, K. M. A. Chan, T. M. Daw, E. Garmendia, E. Gómez-Baggethun, R. S. de Groot, G. M. Mace, B. Martín-López, and J. Phelps. 2017. Off-stage ecosystem service burdens: a blind spot for global sustainability. 
Pielke Jr, R. A. 1998. Rethinking the role of adaptation in climate. Global Environmental Change 8(2):1597170.

Poulin, B., G. Lefebvre, and L. Paz. 2010. Red flag for green spray: adverse trophic effects of Bti on breeding birds. Journal of Applied Ecology 47(4):884-889. https://doi.org/10.1111/j.1365-2664.2010.01821. $\underline{\mathrm{X}}$

Siciliano, G., F. Urban, S. Kim, and P. D. Lonn. 2015. Hydropower, social priorities and the rural-urban development divide: the case of large dams in Cambodia. Energy Policy 86:273-285. https://doi.org/10.1016/j.enpol.2015.07.009

Smit, B., and O. Pilifosova. 2003. Adaptation to climate change in the context of sustainable development and equity. Sustainable Development 8(9):9.

Stringer, L. C., A. J. Dougill, E. Fraser, K. Hubacek, C. Prell, and M. S. Reed. 2006. Unpacking "participation" in the adaptive management of social-ecological systems: a critical review. Ecology and Society 11(2):39. https://doi.org/10.5751/es-01896-110239

Therville, C., U. Brady, O. Barreteau, F. Bousquet, R. Mathevet, S. Dhenain, F. Grelot, and P. Brémond. 2019. Challenges for local adaptation when governance scales overlap. Evidence from Languedoc, France. Regional Environmental Change 19 (7):1865-1877. https://doi.org/10.1007/s10113-018-1427-2

Turner II, B. L., R. E. Kasperson, P. A. Matson, J. J. McCarthy, R. W. Corell, L. Christensen, N. Eckley, J. X. Kasperson, A. Luers, M. L. Martello, C. Polsky, A. Pulsipher, and A. Schiller. 2003. A framework for vulnerability analysis in sustainability science. Proceedings of the National Academy of Sciences 100 (14):8074-8079. https://doi.org/10.1073/pnas.1231335100 